\title{
Tribological Characteristics of Modified Hypo Eutectic Al-Si Alloy
}

\author{
SAJAWAL Hussain ${ }^{\mathrm{a}^{*}}$, MUHAMMAD Mansoor ${ }^{\mathrm{b}}$, \\ REHAN Qayyume ${ }^{c}$, SHAHEED Khan ${ }^{d}$ \\ Institute of industrial control Systems, Rawalpindi-PAKSITAN \\ asajawalhussain09@gmail.com, bmalik01677@yahoo.com crehan1606@gmail.com, \\ dpe_shaheed@hotmail.com
}

Keywords: Al-Si Eutectic Alloy, Modified Si Rich Phase, Tribological Characteristics.

\begin{abstract}
Al-Si eutectic system is a class of important cast alloys accounting for the majority of aluminum parts for different industrial applications. However, in unmodified form, where Si rich secondary phase found in needle shape, it attributes to the lower mechanical strength, ductility and wear characteristics. In present work, Al-9 wt. \%Si alloy was prepared in unmodified and modified form, where modification was carried out using mixtures of chloride and fluoride fluxes. The modification process rectified the needle like silicon rich secondary phase into acicular shape, whose effect upon the tribological characteristic of the alloy were studied using pin-on-disc method. It was found that the coefficient of friction was reduced in modified alloy, moreover wear rate was also decreased. The main feature of wear scar was laminates. In case of modify alloy the laminates were of uniformly formed small sized, as opposed to non-uniform predominately large sized smooth segments with cracked edges. It was postulated that these non-uniform smooth laminates were formed due to smearing resulted in high coefficient of friction and wear rate. The altered tribological characteristics were attributed to the morphology of the silicon rich secondary phase i.e. the acicular shape.
\end{abstract}

\section{Introduction}

Aluminum is the most frequently used metal in the non-ferrous group with currently 55.04 million tones consumption annually in the world 2015[1], due to a good combination of properties like light weight, corrosion resistance and strength. Although use of wrought aluminum is widespread in aerospace industry, nevertheless cast aluminum is being used more and more in automotive industry especially from last two decades when production of cars started [2]. About $24 \%$ of all aluminum is being used in the cast form to make complex shapes like engine blocks, piston, and other parts [3].

These casting must have good mechanical properties and castability. The latter property means casting without solidification cracking, with high molten metal fluidity and low porosity. Aluminum silicon alloys forms the most important group of cast aluminum alloys with good castability due to high heat of fusion of silicon which is 4.5 times than aluminum [4].

Cast aluminum silicon alloys are used with different silicon compositions forming eutectic and near eutectic alloys. Although silicon serves to improve the processing by improving fluidity of molten metal, unfortunately the alloys are associated with low strength, ductility and machinability [1]. Aluminum silicon alloy used in the combustion engine where typically temperature reaches between from 470 to $620 \mathrm{~K}$ [2], such high temperature and stresses might result in scuffing during operation $[3,4]$. All these properties are structure sensitive and can be improved by changing or modifying the lamellar microstructure of the alloys to fibrous morphology by the controlled addition of so called modifier for example sodium and/or strontium [5]. At present, behavior of the modified alloys is unclear for wear properties [6]. For some authors [4] the alloy modification has very little effect on wear, others [7] say that refinement in the microstructure may results in increased wear resistance.

As Al-Si system provides the most important casting alloys and accounts for more than $90 \%$ [8] of cast aluminum parts for different industries but offers poor machinability, strength ductility and wear characteristics in unmodified form. Therefore, a study was conducted in order to assess the effect of modifier on the wear (tribological) properties of aluminum silicon alloy LM-9. 


\section{Experimental Work}

Alloy preparation. The hypo-eutectic aluminum silicon alloy used for this study conforms to the chemical composition of LM-9 cast aluminum alloy. The chemical composition of the experimental alloy is given in Table 1 along with LM-9 standard composition [9].

Table 1 Chemical Composition of Experimental Hypo Eutectic alloy [w.t \%].

\begin{tabular}{|c|c|c|c|c|c|c|c|c|}
\hline & Mn & Mg & $\mathbf{S i}$ & $\mathbf{F e}$ & $\mathbf{C u}$ & $\mathbf{N i}$ & Zn & Al \\
\hline LM-9 & $\begin{array}{c}0.3- \\
0.7\end{array}$ & $\begin{array}{c}0.2- \\
0.6\end{array}$ & $8-12$ & $<0.6$ & $<0.2$ & $<0.1$ & $<0.1$ & Bal. \\
\hline Experimental Alloy & 0.38 & 0.15 & 8.5 & $\leq 0.3$ & $\leq 0.2$ & Nil & $\leq 0.16$ & Bal. \\
\hline
\end{tabular}

The melt was prepared using electric resistance heating furnace. In order to add the essential alloying elements such as $\mathrm{Si}, \mathrm{Mn}$, and $\mathrm{Mg}$, the master-alloys of $\mathrm{Al}-\mathrm{Si}, \mathrm{Al}-\mathrm{Mn}$ and $\mathrm{Al}-\mathrm{Mg}$ were used, respectively. The raw materials for the alloy were thoroughly cleaned before charging into the furnace to avoid any undesirable material and impurities. The materials were then dried placing in box furnace to eliminate moisture which could cause. The preheating of Al-Mg alloy was done at 150 to $200{ }^{\circ} \mathrm{C}$ for 20 minutes, whereas the rest of the charging materials were pre-heated at 25 to $300 \mathrm{C}$ for 90 minutes

In the first step the pre-heated pure aluminum was added in a pre-heated graphite crucible at 600 to $700 \mathrm{C}$ in an electric resistance furnace. Following this a melting flux of $0.5 \mathrm{wt} . \%$ of the melt was added. After the aluminum has completely melted, a pre-weighed amount of Al-Mn alloy was incorporated, followed by the addition of Al-Mg alloy. In order to perform degassing of the melt, a two stage degassing was done in which at the first stage Gegasser-190 tablets were used followed by vacuum degassing at $10^{-2} \sim 10^{-3}$ mbar pressure.

The melt was then modified using a chemical mixture of fluxes consists of salts such as $\mathrm{KCl}$, $\mathrm{NaCl}, \mathrm{NaF}$. The flux mixture used for this work was comprised of 63 wt. \% NaCl. 12 wt. \% $\mathrm{KCl}$ and $25 \mathrm{wt}$. \% of NaF. Flux was added by $3 \mathrm{wt}$. \% of the melt while maintaining the melt at a superheated temperature between $730 \sim 740{ }^{\circ} \mathrm{C}$. The melt was then held at this temperature for 10 to 15 minutes while slowly stirred with steel plunger without breaking the surface layer of modifier flux. Finally, the drossy slag was skimmed off from the top and molten metal was poured into sand mold. Wear Testing. In order to characterize the tribological properties of cast aluminum silicon eutectic alloy, wear tests were conducted using pin on disc apparatus. Two kind of cast samples (discs: $25 \mathrm{~mm}$ diameter and $6 \mathrm{~mm}$ thickness) one in the un-modified and other in the modified microstructure were machined. The surface finishing of the discs after grinding is given in Table 2 . Samples were then tested under identical test conditions using ball made of 100Cr6 (AISI 52100) bearing steel under a normal load of $10 \mathrm{~N}$ and a radius of $5 \mathrm{~mm}$. The sliding speed used during tests was $100 \mathrm{~m} / \mathrm{s}$ and tests were continued for a sliding distance of $100 \mathrm{~m}$. All of the tests were conducted at room temperature of $25{ }^{\circ} \mathrm{C}$ and relative humidity of $50 \%$. The volume loss for each sample during the test was calculated by measuring the weight loss through measuring the weight of the discs before and after the test using electronic digital weight balance with an accuracy of four decimal points. The Vickers hardness of all samples was measured using 30-gram load for 10 seconds. Wear rates for each sample was calculated using following equation 1 :

$$
\text { Wear rate }=\frac{V}{L F} \text {. }
$$

where, $\mathrm{V}$ is the volume of wear debris produced in $\mathrm{mm}^{3}, \mathrm{~L}$ is the sliding distance in meter, and $\mathrm{F}$ is the normal force applied during test in newton.

Stereo, optical, and scanning electron microscope was used in order to characterize and to study the wear mechanisms. 


\section{Results and Discussion}

The addition of sodium and calcium in the form of salts (flux) into cast aluminum silicon eutectic alloy resulted in modification of morphology of eutectic aluminum silicon eutectic phase.

Table 2 Surface Finishing and Hardness of Un-modify and Modify test samples.

\begin{tabular}{|c|c|c|}
\hline Sample & Surface roughness, $\mathbf{R}_{\mathbf{a}}(\boldsymbol{\mu m})$ & Hardness $(\mathbf{H v})$ \\
\hline Un-modify & $0.16 \pm 0.04$ & 55 \\
\hline Modify & $0.16 \pm 0.03$ & 92 \\
\hline
\end{tabular}

Modification was attributed to the transformation of the phase from needle like morphology to globular shape. The microstructure for modified alloy is shown in Fig. 1a also shown is unmodified structure for comparison purpose, Fig. $1 \mathrm{~b}$.
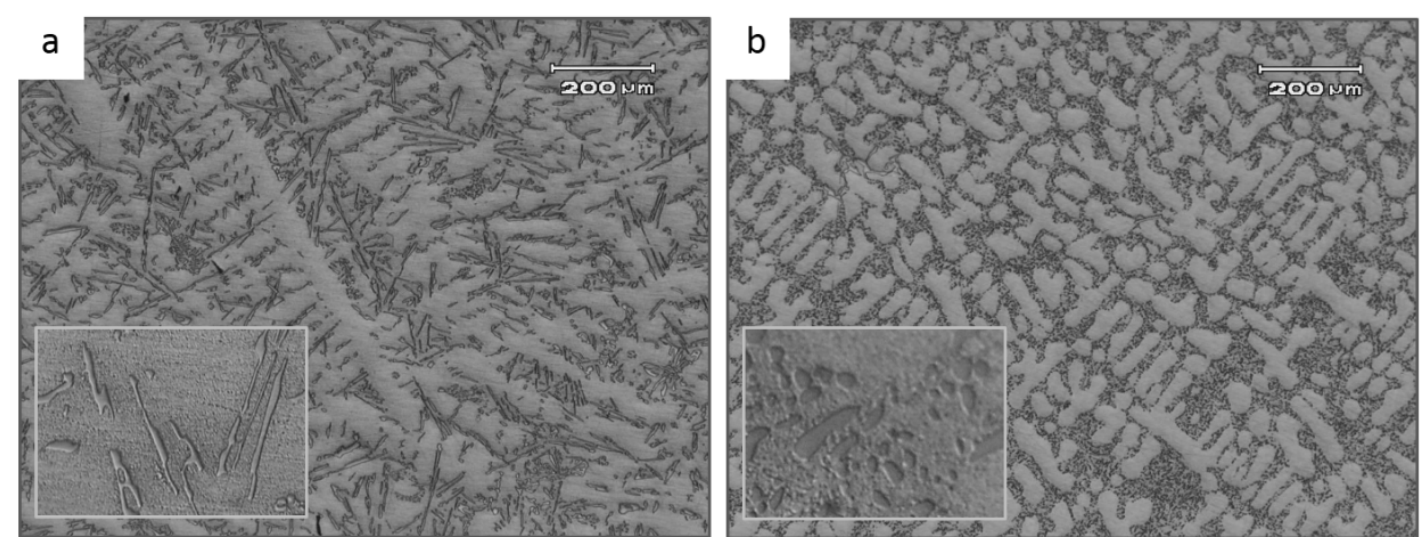

Fig. 1 Optical micrographs in as polished form of: a) un-modified, b) modified alloys.

Completely modified sample showed higher hardness, which was nearly two times greater than un-modified sample. This increase in hardness could be linked to the refinement effect of flux on eutectic aluminum silicon phase in the microstructure. The hardness results are shown in Table 2.

The wear response of eutectic alloys using dry sliding conditions is shown in Figure $2 \mathrm{a}$ to $2 \mathrm{~b}$. The coefficient of friction $(\eta)$ of un-modified sample was increased very rapidly to a value of 0.77 , it than dropped and recovered several times before it reached to its steady-coefficient of friction value of 0.30 . In the case of modified sample, it showed a lower static coefficient of friction which is 0.57. Furthermore, it also traveled more distance to reach static coefficient of friction than unmodified alloy, it then drops off and obtained its steady value of coefficient of friction (0.15), which is twice lower than un-modified sample.
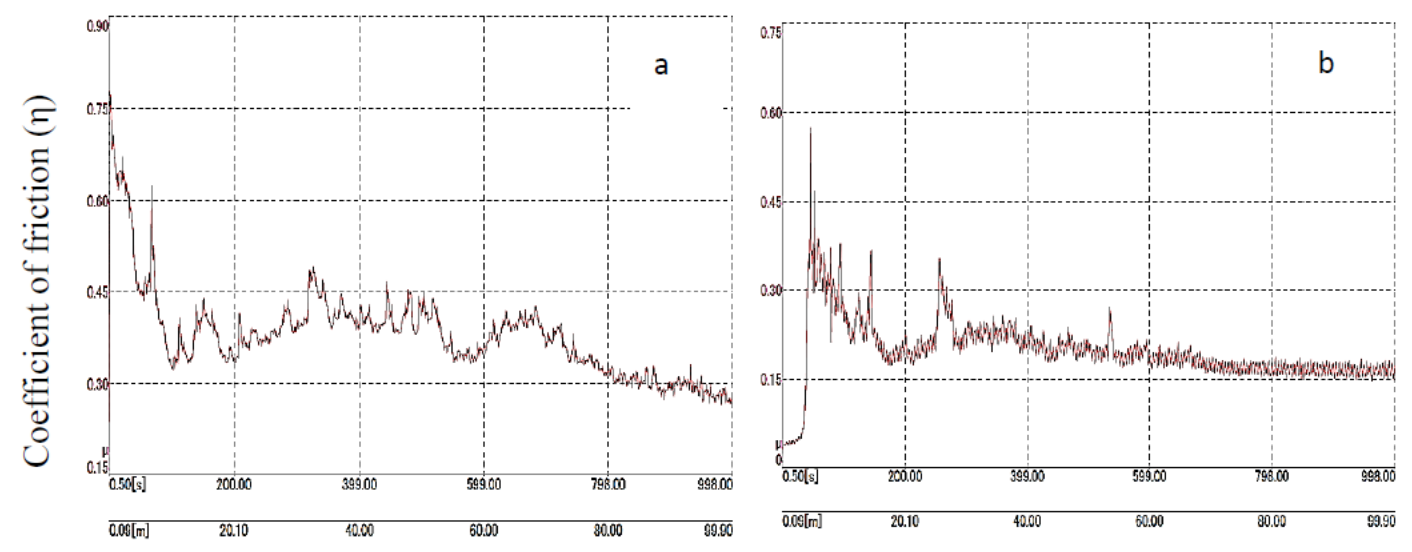

Fig. 2 The coefficient of friction ( $\eta$ ): a) un-modify alloy, b) modify alloy 
This decrease in friction coefficient of the modified alloy could be related with two factors: first the modification of microstructure as can be observed in Fig.2b resulted in change in morphology of Al-Si eutectic phase from needle to globular shape along with refinement in microstructure by providing more nucleation sites to nucleate silicon particles. This refinement and globular morphology of silicon particles in microstructure, acted as a uniform lubricating medium to avoid scuffing [10], and therefore; caused the decrease in steady-coefficient of friction. Furthermore, the overall increase in hardness of the modified alloy also reduced adhesion during relative motion between the rotating disc and static ball, hence lowered the friction.

The wear rate calculated using Eq. 1 for all samples is shown in Fig.3. The modified alloy displayed decrease in wear rate as much as $50 \%$ when compared with un-modified alloys. The improvement could be attributed to the thorough modification process, which transformed the secondary silicon rich phase into fine dispersed globules; hence increasing their surface area. The fine and hard dispersion caused the reduced contact between the ball and aluminum matrix, which is a softer phase. Increased contact of the ball with harder phase (eutectic silicon) decreased the coefficient friction, consequently lower wear rates were attainable.

Wear Rate for different alloys

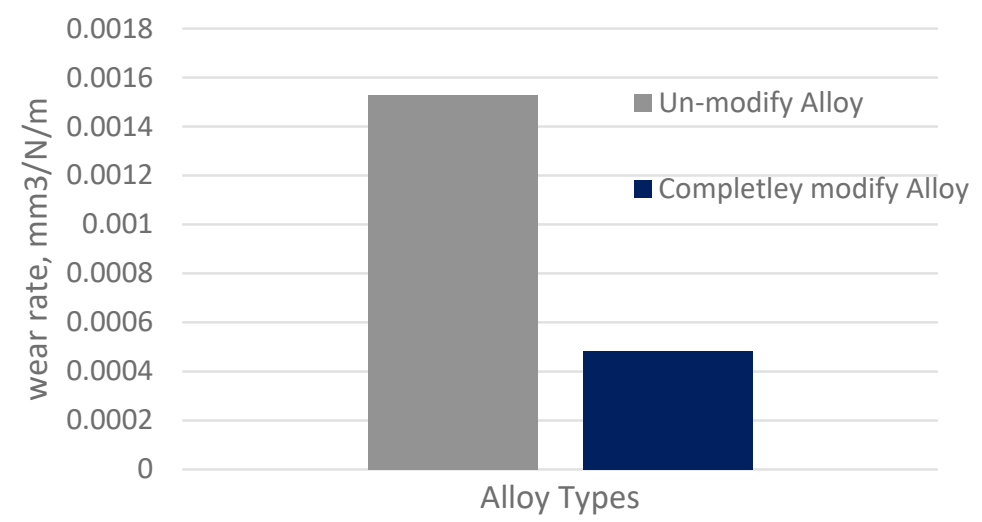

Fig. 3 Wear rate for modified and un-modified alloy, also shown the wear rate for un-modify alloy for comparison purpose.

\section{Topographic Characteristics of Wear Scars.}

Un-modified Alloy. A scanning electron microscope (SEM) was used to study the topological features of the wear scars. The general appearance of the scars was ploughing and lamination. A clear and smooth long segment was seen, which was probably formed due to the traction of the ball (Fig. 4a). At higher magnification, cracks and fissures at the edges of the lamination were revealed. In certain areas the lamination was found detached, which might be occurred when the fissures in the laminations extended their length during wear process to a critical size (Fig. 4b).

Another distinguishable features observed were the "roof tile laminates", which are deposition of the laminates layer-by-layer [11], see Fig. 4b. Such types of laminates are formed under high contact stresses on a soft matrix [3]. As the pair of wear, the hard steel ball and aluminum alloy specimens continued to sliding repeatedly over the initially deposited aluminum, some of the aluminum back transfers. It seems that the process of this buildup of layer on layer was continued until adhesive shear process caused their removal. Although the shear dimples were not observed on laminates, which is in accordance with the findings of Doyle and Turley [12].

Modified Alloy. Contrarily to the unmodified alloy, the wear scars of modified alloy exhibited fine topographic features (Fig. 4c). The ploughing marks were smaller and finer while lamination was not discernable at lower magnification, however at higher magnification fine roof laminates could be seen (Fig. 4d). Another distinct feature was lack of fissures and cracks at the edges of the laminates, showing better wear characteristics of the material.

The main feature associated with both alloy was roof tile laminates. Previous studies [11] postulated the mechanism of formation of laminate is back transfer, in which material is first 
deformed (yielded), and deposited from soft aluminum onto hard steel ball and then is again transferred back during subsequent sliding. The postulation of back transfer was also supported by observation of transverse cracks, which present in a kind of series [11] in un-modify alloy, Fig. 5a and $5 \mathrm{~b}$.
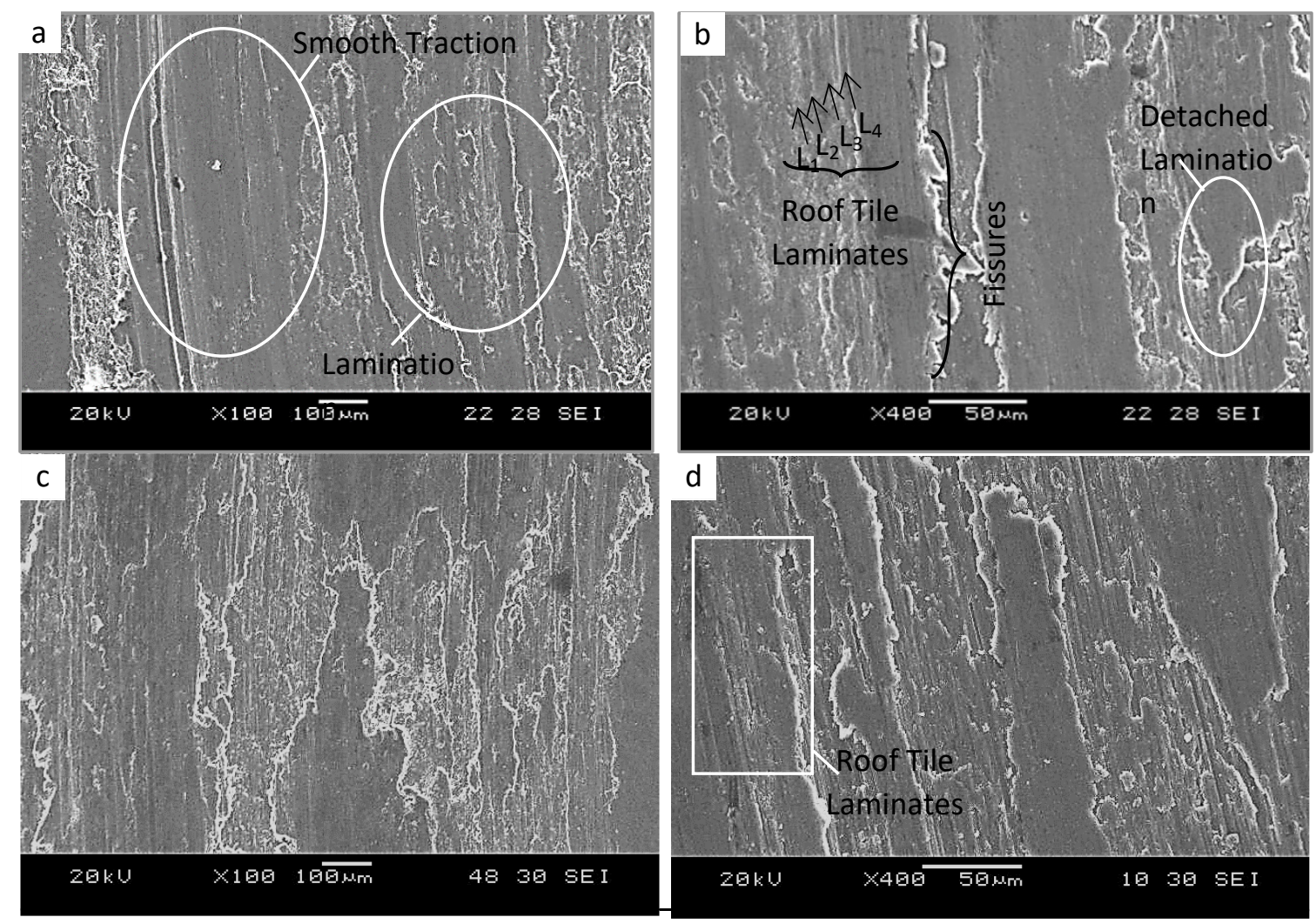

Fig. 4 a to $d$ Topographic features of the wear tracks of various specimens under investigation.

In modified alloys, though roof tile laminates were present, however those were very fine and consistent with the ploughing marks. Additionally, the laminates were not accompanied with fissures and delamination; unlike un-modified alloy, Fig. $4 \mathrm{c}$ and $4 \mathrm{~d}$. Consequently, the seizure was not imminent during sliding due to uniform deformation as indicated by the small evenly roof tile laminates, which could be the reason for the decreased coefficient of friction. Moreover, it could be reasonably inferred that subsequent delamination was reduced due to the decreased contact area between layers in the laminates by the presence of finer and modified silicon particles; resulting lowered wear rate.

While in un-modify alloy, the deformation was not uniform i.e., at locations there were long smooth deposits and at other there were uneven laminates, which resulted in increased seizure and delamination, consequently higher coefficient of friction and wear rate were observed.

Additionally, smooth and long segments with cracked edges can be noted in Fig. 4b. The increased edge cracking could be due to the low work hardenability because of the lower hardness and ductility of the un-modify alloy. The material was possibly flowed in direction normal to the sliding, where severely deformed material cracked at the edges under the influence of the longitudinal stress and then separated from sample [4]. 

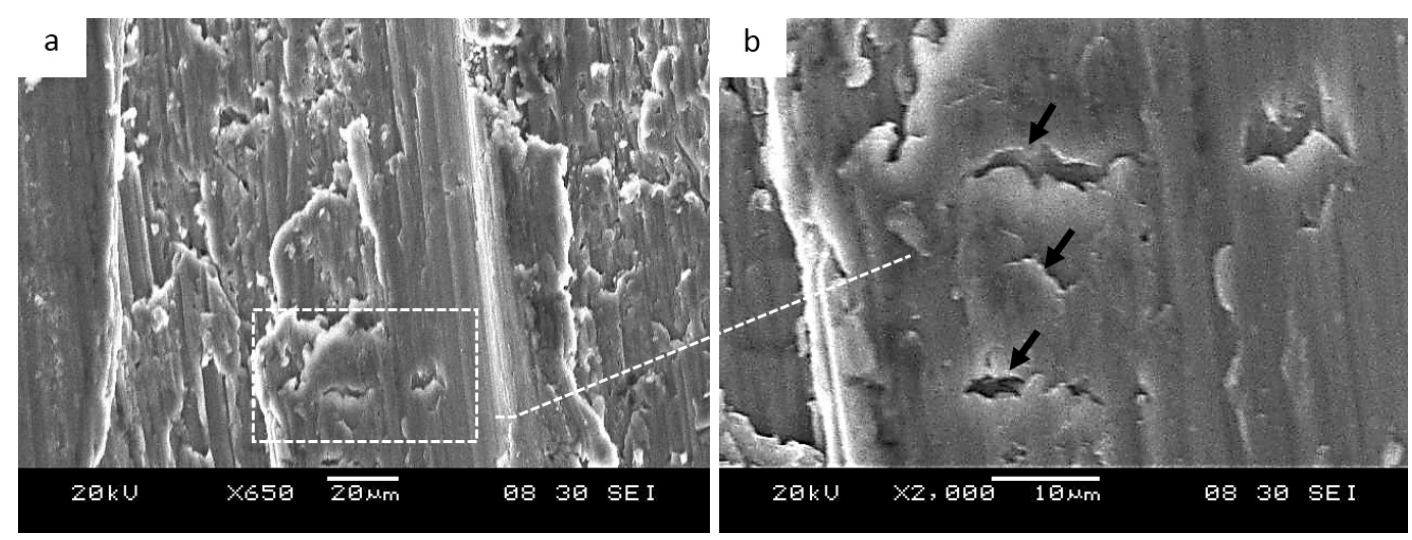

Fig. 5 a\&b SEM images of un-modified alloy showing series of transverse crack.

\section{Conclusion}

Aluminum silicon cast eutectic alloy was effectively modified using flux of sodium and calcium in the form of their salts, in which morphology of eutectic Al-Si phase changed from needle to globular shape. Both coefficient of friction and wear rate were reduced significantly with the modification in the microstructure. The main feature of wear scar was roof tile laminates in both the alloys. It was suggested that laminates were formed by back transfer mechanism. In case of unmodify alloy these were long smooth segments with cracked edges, which were associated with higher seizure and wear rate. The wear scar of completely modify alloy was mainly consists of small sized laminates with smooth edges, which were associated with decreased smearing and therefore, decreased seizure and reduced wear rate.

\section{References}

[1] J. G Kaufman, E. L. Rooy, 2004. Aluminum Alloy Castings: Properties, Processes, and Applications. 1st ed. s.1. ASM International.

[2] M. L. P. Rhodes, 1970. Piston Research and Development Techniques. s.1., s.n.

[3] A. D. Sarkar and J. Clarke, wear characteristics, friction and surface topography observed in the dry sliding of as-cast and age hardening al-si alloys, 75 (1982.) Wear 71-85.

[4] B. N. Pramila Bai, S. K. Biswas And N. N. Kumtekar, Scanning electron microscopy study of worn Al-Si. Wear, 87 (1983) 237-249.

[5] M. Di Sabatino, 2005. Fluidity of aluminium alloys. PhD. Thesis at NTNU. s.1.:s.n.

[6] S. B. Shabel, D. A. Granger, and W. G. Truckner, 1992. Friction and Wear of AluminumSilicon Alloys. In: P. J. Blau, ed. ASM Handbook Volume 18: Friction, Lubrication, and Wear Technology. s.1.: ASM International, pp. 785-794.

[7] T. K. A. Jaleel, N. Raman, S.K. Biswas,and K.K. Murthy, Effect of structural modification and load on the wear of a hypereutectic aluminium-silicon alloy. Alum., 60 (1984) 932-933.

[8] M. Glazoff, V. Zolotorevsky, N. Belov, 2007. Casting Aluminum Alloys. 1st ed. s.1.:Elsevier Science .

[9] British Standard, 1988. Specification for aluminium and aluminium alloy ingots and castings for general engineering purposes. s.1.:BSI.

[10] T. Eyre, Wear Resistance of Metals. Treat. Mater. Sci. Technol., 13 (1979) 363-442.

[11] J.Clarke and A.D.Sarkar, Topographical features observed in a scanning electron microscopy study of aluminium alloy surfaces in sliding wear. Wear, 69 (1981) 1-23.

[12] E. D. Doyle and D. M. Turley, Delamination effects in grinding. Wear, 51 (1978) 269-278. 